fermentation is also used as a condiment in various curries. The shelf-life of bastenga is up to 2 years, with proper measures of handling the shoots while fermenting. The Ao Naga tribe believes that use of hands should be avoided while fermenting; alternatively a spoon could be used. Also, the local people believe that only an expert should be involved in processing the bamboo shoots as the quality of the product may degrade or cause spoilage (oxidation) due to careless handling. The locals believe that bastenga has properties that neutralizes certain allergens that may be present while cooking; however, excessive use leads to stomach ailments owing to its acidic nature. The brine/juice is used as a stimulant to treat bee stings.

'Generous heart, generous plate' is the story of every Naga kitchen. Bastenga marks its popularity in the tribal homes, which is evident by the markets that continue to thrive in the region. The overlapping of traditional methods of preparation among the various tribes could be due to the availability of similar resources in the region. However, the selective taste on traditional gastronomy contributes to strengthening culinary culture and fermentation techniques in Nagaland.

Competing interests: The authors declare no conflict of interest.

1. Sundriyal, R. C., Upreti, T. C. and Varuni, R., Bamboo and cane resource utilization and conservation in the Apatani Plateau, Arunachal Pradesh, India: implications for management. J. Bamboo Rattan, 2002, 1(3), 205-246.

2. Bystriakova, N., Kapos, V. and Lysenko, I., Bamboo diversity. UNEP-WCMC/INBAR, 2004.

3. FSI, The India State of Forest Report 2011, Forest Survey of India, 2011.

4. Bhatt, B. P., Singha., L. B., Sachan, M. S. and Singh, K., Commercial edible bamboo species of the North-Eastern Himalayan Region, India. Part 1: Young shoot sales. J. Bamboo Rattan, 2004, 3(4), 337-364.

5. Kithan, L. N., Socio-economic importance of bamboo among the Nagas of Nagaland. J. Human Ecol., 2014, 48(3), 393-397.

6. Sarkar, J. and Sundriyal, R. C., Indigenous uses, management and conservation of bamboo resource in Arunachal Pradesh, North East India. Bamboo J., 2002, 19, 24-39.

7. Deb, C. R. and Jamir, B., Ethnic fermented foods and products of Nagaland, India. J. Food Chem. Nanotechnol., 2020-079.

ACKNOWLEDGEMENT. We thank the DBT, Department of Science and Technology, New Delhi for providing financial assistance under the grant No. BT/PR12956/NDB/39/504/2015. We also thank the UGC-SAP (DRS-III), DST-FIST (level 1) and the Botany Department, Nagaland University for providing the necessary facilities. We are also grateful to all the women folks interviewed for sharing their valuable knowledge and special thanks to Mr Chingmei Semdok, Miss Thejano Ngullie and Miss Elina Yeptho for their contribution during the fieldwork.

Received 25 November 2020; accepted 7 December 2020

doi: $10.18520 / \mathrm{cs} / \mathrm{v} 120 / \mathrm{i} 4 / 715-718$

\section{A new modified nutrient media for cultivation of Actinobacteria}

\author{
A. N. Ganeshamurthy*, B. Saritha, T. K. Radha \\ and P. Panneerselvam \\ Division of Soil Science, ICAR-Indian Institute of Horticultural \\ Research, Hessaraghatta, Bengaluru 560 089, India
}

The growth of Actinobacteria was evaluated in a new modified nutrient agar media (MNA) supplemented with $1 \%$ sodium chloride $(\mathrm{NaCl})$ and compared with the universally accepted media which are under regular use. Thirteen different Actinobacterial isolates were evaluated for their growth in both solid and liquid media in MNA along with four regularly used media ISP-2, kenknight, starch casein and nutrient media. Results indicated that eight isolates (Streptomyces bulli, Streptomyces griseorubens, Streptomyces viridobrunneus, Streptomyces A3, Streptomyces A7, Streptomyces A11, Streptomyces A12 and Streptomyces A13), out of thirteen isolates could grow significantly faster on MNA compared with other solid agar media. Similarly, growth in liquid media recorded by optical density (OD) indicated that three isolates (S. griseorubens, $S$. viridobrunneus and $A 7$ ) showed significantly higher OD followed by ISP-2, nutrient, starch casein and kenknight broth after seven days of incubation. All the isolates except $S$. viridobrunneus and Streptomyces A12 could tolerate $\mathrm{NaCl}$ concentration upto $6 \%$ in liquid modified nutrient broth. The present study showed that Actinobacteria can be successfully grown faster with full pigmentation at $1 \% \mathrm{NaCl}$ concentration and they can tolerate up to $5 \%$ NaCl concentration, in the new proposed MNA media.

Keywords: Actinobacteria, modified nutrient agar media, optical density, sodium chloride.

PREPARATION of suitable culture medium is one of the prerequisites to study microorganisms and for their commercial exploitation. Selection of the medium is essential for isolation and multiplication. Bacterial media can be simple or complex synthetic media, where they vary in nutritional make-up. Different microorganisms thrive at different environments and have variety of growth requirements - like $\mathrm{pH}$, osmotic conditions, nutrients and temperature. Due to lack of sufficient variability of media composition, replication of the exact environmental conditions in the laboratory and in commercial multiplication is difficult ${ }^{1}$. Several selective and differential media have been formulated, with varying components that differentiate one group of organism from another, for example, MacConkey Agar and Blood Agar. Supplementing with additional specific components, alternative media were prepared to help in further selective culturing of bacteria.

\footnotetext{
*For correspondence. (e-mail: angmurthy@gmail.com)
} 
For example, for cultivating mycobacteria, Petergnani medium and Dorset medium are used. Dorset medium consists of egg white and egg yolk and a solution of sodium chloride $(\mathrm{NaCl})^{2}$. Essentially, life is connected with the growth phenomenon which can be viewed scientifically by cellular level underlying increase in length, volume, division and replication. On the other hand, growth phenomenon can be viewed with the increase in number of individuals which indicates the population size $^{3}$. For any commercial production of cultures, survival and uninterrupted growth is essential. This depends upon an adequate supply of nutrients and a favourable growth environment ${ }^{4}$. Actinobacteria are group of microorganisms which are slow growing and need complex media for their growth and cultivation. The usual recommended media for cultivation of Actinobacteria are International Streptomyces Project (ISP) media, kenknight media (KK) and starch casein agar (SCA) media. Actinobacteria are grown on commercial scale for the production of antibiotics. Their exploitation in agriculture as growth promoters and nutrient mobilizers is also on the rise. Recently, it was reported that these Actinobacteria also produce plant growth promoting attributes ${ }^{5,6}$ such as plant growth hormones (IAA and $\mathrm{GA}_{3}$ ), phosphate solubilization, siderophore production and chitin degrading activity. Hence, they found profound use in industrial production. However, one of the drawbacks in Actinobacterial cultivation is its slow growth and need of complex compounds in traces for which media preparation is time consuming. At present nutrient agar a basic culture medium is in use for the cultivation of bacteria. Its use in Actinobacteria multiplication is not available. Reports however, are available on the growth of Actinobacteria on complex media. Hence, the present study was initiated to find alternative simple media which provides basic nutrients for faster growth of Actinobacteria.

Thirteen different Actinobacteria isolates were collected from the culture repository of the Soil Microbiology Lab, Division of Soil Science and Agricultural Chemistry, ICAR-Indian Institute of Horticultural Research, Bengaluru, India for this study. Among these, three were in use as biofertilizer consortium, viz. Streptomyces bulli, Streptomyces griseorubens and Streptomyces viridobrunneus, and ten were new Streptomyces isolates (A1-A7 and A11-A13).

Five media were tested for comparative studies on growth of Actinobacteria. Among the five media, nutrient agar media (NA) and four commonly used media namely ISP media, KK media, SCA media were tested for comparison studies, the composition of which are provided in Table 1.

A test media was prepared with modification in the composition of basic nutrient agar (MNA). The ingredients added in MNA media per $100 \mathrm{ml}$ are as follows: Peptone $-0.5 \mathrm{~g}$; yeast extract $-0.3 \mathrm{~g} ; \mathrm{NaCl}-1 \%$. The composition of MNA media was modified by replacing beef extract with yeast extract and increased the $\mathrm{NaCl}$ concentration from $0.5 \%$ to $1.0 \%$. The $\mathrm{pH}$ was adjusted to 7.0 .

The growth of thirteen Actinobacterial isolates were tested in vitro in both liquid and solid agar medium. The experiment was conducted in two replications. In agar plate assay, a loopful culture of Actinobacteria ( $24 \mathrm{~h}$ old) was streaked on all the five media plates and incubated at $30^{\circ} \mathrm{C}$ for $48 \mathrm{~h}$ and the growth was assessed. In liquid broth assay, a well grown loopful culture of Actinobacteria was inoculated aseptically into $100 \mathrm{ml}$ flasks containing $50 \mathrm{ml}$ of respective media and incubated at room temperature for seven days. The cultures were also assessed for salt $(\mathrm{NaCl})$ tolerance on modified nutrient broth by inoculating cultures at different concentrations of $\mathrm{NaCl}(2 \%, 3.0 \%, 4.0 \%, 5.0 \%$ and $6.0 \%)$ and the tolerance was assessed based on the growth of cultures after seven days of inoculation.

After seven days of incubation, the thick mat of culture broth was first sonicated (PCi Analytics, 500F) to obtain a uniform suspension of Actinobacterial growth. Then this clear and uniform suspension was taken in clean cuvettes and its optical density (OD) was measured at $600 \mathrm{~nm}\left(\mathrm{OD}_{600}\right)$ by UV-VIS spectrophotometer. The $\mathrm{OD}_{600}$ values were recorded in inoculated and uninoculated flasks.

The results on the growth of Actinobacteria on different media, viz. MNA, ISP-2, SCA, KK and NA are presented in Table 2 . After $72 \mathrm{~h}$ of incubation, eight isolates,

Table 1. Formulation and composition of the media

\begin{tabular}{|c|c|}
\hline & $\mathrm{g} \mathrm{l}^{-1}$ \\
\hline \multicolumn{2}{|l|}{ ISP-2 media } \\
\hline Dextrose & 4.0 \\
\hline Yeast extract & 4.0 \\
\hline Malt extract & 10.0 \\
\hline Agar & 20.0 \\
\hline $\mathrm{pH}$ & 7.0 \\
\hline \multicolumn{2}{|l|}{ Kenknight Agar } \\
\hline Dextrose & 1.0 \\
\hline $\mathrm{KH}_{2} \mathrm{PO}_{4}$ & 1.1 \\
\hline $\mathrm{NaNO}_{3}$ & 0.1 \\
\hline $\mathrm{KCl}$ & 0.1 \\
\hline $\mathrm{MgSO}_{4}$ & 0.1 \\
\hline Agar & 20.0 \\
\hline $\mathrm{pH}$ & 7.0 \\
\hline \multicolumn{2}{|l|}{ Starch Casein Agar } \\
\hline Soluble Starch & 10.0 \\
\hline Casein & 1.0 \\
\hline Agar & 20.0 \\
\hline $\mathrm{pH}$ & 7.0 \\
\hline \multicolumn{2}{|l|}{ Nutrient agar } \\
\hline Peptone & 5.0 \\
\hline Beef Extract & 3.0 \\
\hline $\mathrm{NaCl}$ & 5.0 \\
\hline Agar & 20.0 \\
\hline $\mathrm{pH}$ & 7.0 \\
\hline
\end{tabular}


Table 2. Growth of Actinobacteria on different media

\begin{tabular}{|c|c|c|c|c|c|c|c|c|c|}
\hline \multirow[b]{2}{*}{$\begin{array}{l}\text { Different } \\
\text { media }\end{array}$} & \multirow[b]{2}{*}{$\begin{array}{c}\text { Physical } \\
\text { state of media }\end{array}$} & \multicolumn{8}{|c|}{ Growth of Actinobacterial isolates } \\
\hline & & $\begin{array}{c}\text { Strepto- } \\
\text { myces } \\
\text { bulli }\end{array}$ & $\begin{array}{l}\text { Streptomyces } \\
\text { griseorubens }\end{array}$ & $\begin{array}{c}\text { Streptomyces } \\
\text { viridobrunneus }\end{array}$ & $\begin{array}{c}\text { Strep- } \\
\text { tomyces } \\
\text { A3 }\end{array}$ & $\begin{array}{c}\text { Strep- } \\
\text { tomyces } \\
\text { A7 }\end{array}$ & $\begin{array}{c}\text { Strepto- } \\
\text { myces } \\
\text { A11 }\end{array}$ & $\begin{array}{c}\text { Strepto- } \\
\text { myces } \\
\text { A12 }\end{array}$ & $\begin{array}{c}\text { Strepto- } \\
\text { myces } \\
\text { A13 }\end{array}$ \\
\hline \multirow[t]{2}{*}{ MNA } & Solid agar & ++++ & +++ & ++++ & ++++ & ++++ & ++++ & ++++ & ++ \\
\hline & Liquid broth & ++ & ++ & $++++^{\mathrm{a}}$ & ++++ & $++++^{\mathrm{b}}$ & +++ & ++++ & +++ \\
\hline \multirow[t]{2}{*}{ ISP-2 } & Solid agar & ++ & ++ & ++ & +++ & ++ & +++ & ++++ & ++ \\
\hline & Liquid broth & + & + & ++ & ++++ & ++ & ++ & + & ++++ \\
\hline \multirow[t]{2}{*}{ KK } & Solid agar & ++ & + & ++ & ++ & ++ & + & + & + \\
\hline & Liquid broth & +++ & +++ & ++ & ++ & ++ & +++ & +++ & ++ \\
\hline \multirow[t]{2}{*}{ SCA } & Solid agar & ++ & + & ++ & + & + & - & + & - \\
\hline & Liquid broth & ++++ & + & +++ & - & ++ & ++ & ++ & + \\
\hline \multirow[t]{2}{*}{ NA } & Solid agar & - & - & + & ++++ & ++++ & +++ & +++ & ++ \\
\hline & Liquid broth & + & + & ++ & ++++ & +++ & +++ & +++ & ++ \\
\hline
\end{tabular}

++++, Excellent; +++, Good; ++, Medium; +, Normal; -, No growth.

${ }^{\mathrm{a}}$ Retained green colour of respective culture; ${ }^{\mathrm{b}}$ Retained brown colour of respective culture.
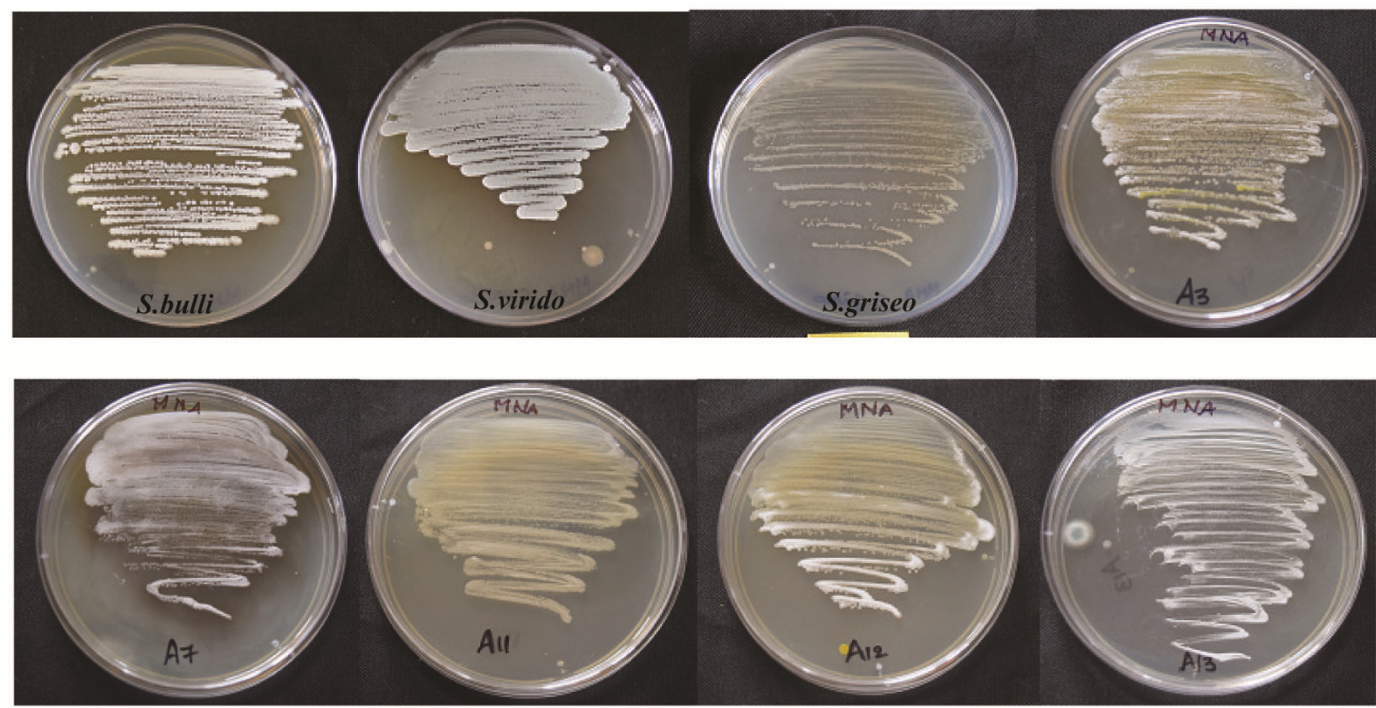

Figure 1. Cultural characteristics of the Actinobacteria grown on new (MNA) medium for $48 \mathrm{~h}$ at $30^{\circ} \mathrm{C}$. (Note: Brown pigment production by Streptomyces A7 isolate was observed only on MNA plate.)

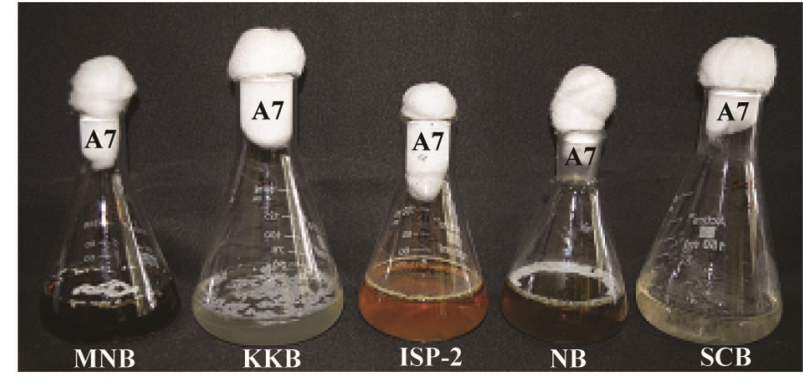

Figure 2. Growth of the isolate Streptomyces A7 in different media broth after 4 days at $30^{\circ} \mathrm{C}$. (Note: Brown pigment production by $\mathrm{A} 7$ isolate was observed only in MNA broth.)

viz. S. bulli, S. griseorubens, S. viridobrunneus, Streptomyces A3, Streptomyces A7, Streptomyces A11, Streptomyces A12 and Streptomyces A13, were able to grow well on MNA, ISP-2 and KK agar media compared with SCA and NA media. Further, all the three commercial cultures (S. bulli, S. griseorubens and S. viridobrunneus) grew well within $24 \mathrm{~h}$ on MNA, whereas the same cultures took $48 \mathrm{~h}$ to attain similar growth on commonly used KK agar for mass production. Seven isolates recorded excellent growth in MNA plates and medium growth in one isolate (Streptomyces A13) compared with any other tested media (Figure 1). The remaining five isolates showed growth only in MNA plates and no growth in any of the other tested media (data not shown).

Significant growth of Actinobacterial cultures (Streptomyces A3, Streptomyces A7, Streptomyces A11, Streptomyces A12 and Streptomyces A13) was observed in MNA liquid media followed by ISP-2 and KK agar media (Figure 2). Eight isolates showed good turbid growth in MNA liquid broth during the incubation period. 
Table 3. Tolerance of Actinobacterial cultures to different $\mathrm{NaCl}$ concentrations on modified nutrient broth

\begin{tabular}{lccccc}
\hline Actinobacteria & $\mathrm{NaCl} 2 \%$ & $\mathrm{NaCl} 3 \%$ & $\mathrm{NaCl} 4 \%$ & $\mathrm{NaCl} 5 \%$ & $\mathrm{NaCl} 6 \%$ \\
\hline S. bulli & ++++ & ++++ & +++ & ++ & + \\
S. griseorubens & +++ & +++ & +++ & + & + \\
S. viridobrunneus & ++++ & ++++ & ++ & ++ & - \\
Streptomyces A3 & ++++ & ++++ & ++++ & ++ & + \\
Streptomyces A7 & ++++ & +++ & ++ & ++ & + \\
Streptomyces A11 & +++ & +++ & ++ & + & + \\
Streptomyces A12 & ++++ & ++++ & +++ & ++ & + \\
Streptomyces A13 & +++ & +++ & ++ & ++ & + \\
\hline
\end{tabular}

Data shown is the result of two replications.

++++, Excellent; +++, Good; ++, Medium; +, Normal; -, No growth.

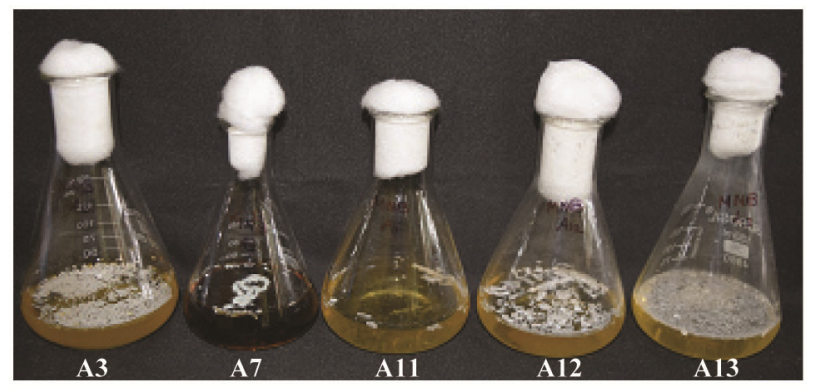

Figure 3. Growth of the Actinobacteria in new MNA liquid broth after 4 days at $30^{\circ} \mathrm{C}$.

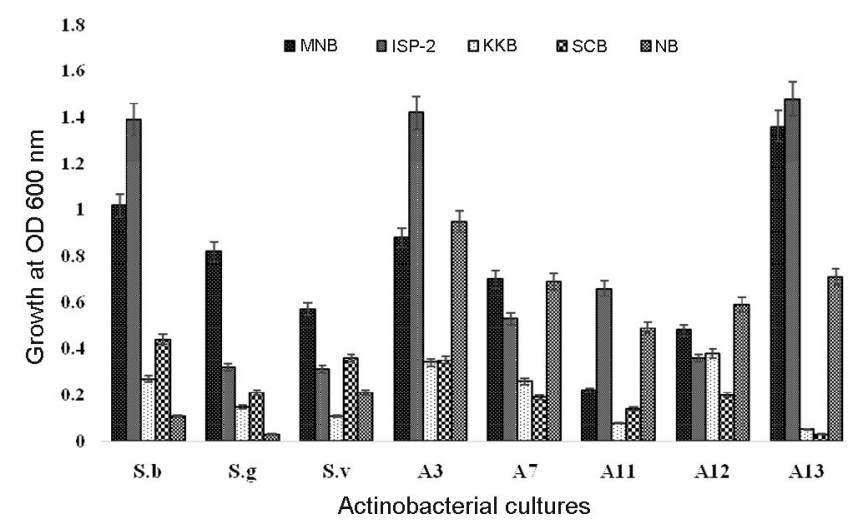

Figure 4. Effect of new modified nutrient agar on Actinobacterial growth.

Interestingly, cultures of S. viridobrunneus and Streptomyces A7 could retain the colony colour of green and brown respectively, which was absent in other media broth (Table 2). The production of dark brown pigmentation in Streptomyces A7 inoculated in new MNA broth was intense which was completely absent in other media broth (Figures 2 and 3). The commercial cultures $S$. bulli and $S$. griseorubens showed no growth in nutrient agar whereas A11 and A13 did not grow on SCA media (Table 2).

Tolerance of Actinobacterial cultures at different concentrations of $\mathrm{NaCl}$ (Table 3) showed that the commer- cialized cultures of $S$. bulli, S. griseorubens and other Streptomyces spp., like Streptomyces A3, Streptomyces A7, Streptomyces A12 and Streptomyces A13 could tolerate $\mathrm{NaCl}$ concentration up to $6 \%$, whereas $S$. viridobrunneus and Streptomyces A11 could tolerate $\mathrm{NaCl}$ concentration upto $5 \%$ on MNA broth.

Actinobacterial culture growth measured spectrophotometrically after seven days of incubation, showed variable $\mathrm{OD}_{600}$ values (Figure 4). Among the eight isolates grown in MNA broth, three cultures of $S$. griseorubens, S. viridobrunneus and Streptomyces A7 recorded significantly higher $\mathrm{OD}_{600}$ values of $0.82,0.57$ and 0.70 compared with other media. Whereas the cultures S. bulli (1.02) and Streptomyces A13 (1.36) also showed significantly higher $\mathrm{OD}_{600}$ when compared with other media except in ISP-2 media (Figure 4). The lowest OD $_{600}$ were recorded in cultures grown on nutrient broth, kenknight and starch casein broth.

The new modified nutrient agar media (MNA) recorded good growth within relatively short time in terms of optical densities and visible growth indicating that the new media is most suited for the growth of these Actinobacteria. It was also found that the rapid growth observed in the MNA medium might be due to the increased concentration of $\mathrm{NaCl}(1 \%)$ which explains the need of sodium requirement for Actinobacterial growth. Similar observations were made by some researchers with respect to sodium requirement for bacterial and Actinobacterial growth $^{7-9}$. Sistrom ${ }^{9}$ observed the rapid growth of Rhodopseudomonas spheroides after adding a little $\mathrm{NaCl}$ to the medium containing an artificial mixture of amino acids. MacLeod et al. ${ }^{8}$ mentioned that two of the nonmarine bacteria examined by him required sodium. Some of the earlier studies on the beneficial effect of sodium on the growth of Bacillus subtilis ${ }^{7}$ and Escherichia coli ${ }^{10}$ were difficult to evaluate because of the complexity of the basal media used. Among the blue-green algae, species of Synechococcus, Chroococcus and Oscillatoria ${ }^{11}$ and Anacystis and Anabaena ${ }^{12}$ have been shown to require sodium for growth. The same is probably true for Microcystis aeruginosa ${ }^{13}$. In our study Actinobacterial cultures showed optimum growth at $1 \% \mathrm{NaCl}$ concentration and 
exhibited tolerance up to $6 \%$ concentration. Similarly, studies on marine Actinomycete Streptomyces rochei (MTCC 10109) showed optimum growth at $2 \% \mathrm{NaCl}^{14}$, but exhibited maximum tolerance up to $6 \% \mathrm{NaCl}$. Although, Actinomycetes can use variety of organic nutrients, often special media are preferable ${ }^{15}$. Similar studies by Bhave et al. ${ }^{16}$ on isolate of Streptomyces radiopugnans strain MTCC5447 from Antarctica soil showed the requirement of $\mathrm{NaCl}$ up to $3 \%(\mathrm{w} / \mathrm{v})$ for its proper growth. Recent work by Manal $^{17}$ on isolation of halophilic Actinobacteria on a new starch, glucose, yeast extract (SGY) media supplemented with $10 \% \mathrm{NaCl}$ reported highest growth within short period of incubation when compared to other traditionally used culture media. Similarly the new MNA media developed and tested in this study also proved effective for growth and multiplication of Actinobacterial cultures.

The present study revealed that the components in new MNA medium enhanced and stimulated the growth of Actinobacteria under increased $\mathrm{NaCl}$ concentration (1\%) in relatively short period of time $(24-48 \mathrm{~h})$, with high amount of growth compared to other media (ISP-2, KK agar, SCA and NA media). Hence, the new MNA medium can be used as an alternative to the traditional media for both laboratory studies and for commercial production.

1. Basu, S., Bose, C., Das, N., Das, D., Pal, M. and Khurana, S., Evolution of bacterial and fungal growth media. Bioinformation, 2015, 11, 182-184.

2. Wasas, A. D. et al., Use of Dorset egg medium for maintenance and transport of Neisseria menigitidis and Haemophilus influenzae type b. J. Clin. Microbiol., 1999, 37, 2045.

3. Widdel, F., Theory and measurement of bacterial growth. Grundpraktikum Mikrobiologie, 2010, 4, 1-11.

4. Cappuccino, J. C. and Sherman, N., Microbiology - A Laboratory Manual, Longman, USA, 1999, 4th edn.

5. Poovarasan, S., Mohandas, S., Panneerselvam, P., Saritha, B. and Ajay, K. M., Mycorrhizae colonizing actinomycetes promote plant growth and control bacterial blight disease of pomegranate (Punicagranatum L. cv Bhagwa). Crop Prot., 2013, 53, 175-181.
6. Mohandas, S., Poovarasan, S., Panneerselvam, P., Saritha, B., Upreti, K. K., Ranveerkamal and Sita, T., Guava (Psidiumguajava L.) rhizosphere Glomus mosseae spores harboractinomycetes with growth promoting and antifungal attributes. Sci. Hortic., 2013, 150, 371-376.

7. Lipman, C. B., Toxic and antagonistic effects of salts as related to ammonification by Bacillus subtiilis. Bot. Gaz., 1909, 48, 1051425 .

8. MacLeod, R. A., Onofrey, E. and Norris, M. E., Nutrition and metabolism of marine bacteria. I. Survey of nutritional requirements. J. Bacteriol., 1954, 68(6), 680-686.

9. Sistrom, W. R., A requirement for sodium in the growth of Rhodopseudomonas spheroids. J. Gen. Microbiol., 1960, 22, 778-785.

10. Holm, G. E. and Sherman, J. M., Salt effects in bacterial growth. I. Preliminary investigation. J. Bacteriol., 1921, 6(6), 511-519.

11. Allen, M. B., The cultivation of Myxophyceae. Arch. Microbiol., 1952, 17, 34-53.

12. Kratz, W. A. and Myers, J., Nutrition and growth of several bluegreen algae. Am. J. Bot., 1955, 42, 282-287.

13. Gerloff, G. C., Fitzgerald, G. P. and Skoog, F., The minimal nutrition of Microcystis aeruginosa. Am. J. Bot., 1952, 39, 26-32.

14. Reddy, N. G., Ramakrishna, D. P. N. and Raja Gopal, S. V., A morphological, physiological and biochemical studies of marine Streptomyces rochei (MTCC 10109) showing antagonistic activity against selective human pathogenic microorganisms. Asian J. Biol. Sci., 2011, 4, 1-14.

15. Sultan, M. Z., Khatune, N. A., Sathi, Z. S., Bhuiyan, M. S. A. and Sadik, G. M., In vitro antibacterial activity of an active metabolite isolated from Streptomyces species. Biotechnology (Faisalabad), 2002, 1, 100-106.

16. Bhave, S. V., Shanbhag, P. V., Sonawane, S. K., Parab, R. R. and Mahajan, G. B., Isolation and characterization of halotolerant Streptomyces radiopugnans from Antarctica soil. Letts. Appl. Microbiol., 2013, 56, 348-355.

17. Manal, J. K., A new medium for the isolation and enrichment of halophilic actinobacteria. Life Sci. J., 2016, 13(1), 65-71.

ACKNOWLEDGEMENTS. We thank the National Co-ordinator and Project Investigator, ICAR-Network on 'Management of Micronutrient in Horticultural Crops' for funding the project.

Received 3 October 2019; revised accepted 17 November 2020

doi: $10.18520 / \mathrm{cs} / \mathrm{v} 120 / \mathrm{i} 4 / 718-722$ 